\title{
Methodological notes on pandemic virus SARS-CoV-2 research
}

\author{
Gianluigi Zangari del Balzo ${ }^{1}$ (1)
}

Received: 1 July 2020 / Accepted: 3 August 2021 / Published online: 8 September 2021

(c) The Author(s), under exclusive licence to Springer-Verlag GmbH Germany, part of Springer Nature 2021

\begin{abstract}
In the fight against the COVID-19 pandemic, many brilliant results have been achieved, but the thermodynamics of the novel SARS-CoV-2 coronavirus has been completely neglected. This is a serious systematic error, which can compromise the results of the entire pandemic virus SARS-CoV-2 research. In the present work, we therefore study the thermodynamics of SARS-CoV-2 in its environment, from air to endosome and endosome-independent cell entry pathways. In the study of the thermodynamics of the new coronavirus SARS-CoV-2 in air, the presence of pollen, bacteria, other viruses, spores, dust, but more particularly, that of nanoparticles of health interest at the same scale threshold as the spike proteins of the pandemic virus, such as particulate matter, cannot be neglected. This work therefore starts from a comparative study of the air environments in China and Italy, the first countries affected by the infection. Currently, a correlation between the spread of infection and pollution is still very controversial. But our paper is not concerned with this. We propose some methodological notes which lead us to the formulation of a general mathematical apparatus (an energy landscape theory), suitable to explain at the molecular level the energetic configurations of the quasi-species of the pandemic virus SARS-CoV-2 in its environment. We focus on complexes between the viral particle and other objects in its environment at the scale threshold of the spikes of the viral particle. Then, we wondered if such complexes can lead to the generation of more aggressive viral variants and how to predict their populations and energy configurations, in order to plan an adequate prophylaxis.
\end{abstract}

Keywords COVID-19 $\cdot$ SARS-CoV-2 $\cdot$ Thermodynamics $\cdot$ Environment $\cdot$ Pollution $\cdot$ Nanoparticles $\cdot$ Particulate matter

\section{COVID-19 pandemic}

The pandemic caused by the new coronavirus SARS-CoV-2 appeared in Wuhan, the capital of the Chinese province of Hubei, in December 2019.

Immediately after China, SARS-CoV-2 infection hit Italy hard, causing thousands of victims to date. Globally, as of 27 August 2021, there have been 214,468,601 confirmed cases of COVID-19, including 4,470,969 deaths, reported to WHO (Source WHO).

At the beginning of last March 2020, a report by World Wildlife Fund (WWF) Italy "Pandemics and the boomerang effect of the destruction of ecosystems" Pratesi et al. (2020) aroused my curiosity because it proposed a connection between two apparently unrelated topics: "ecology and pandemics." On the same issues, but from another point of view, an interesting video was published on March 20

Gianluigi Zangari del Balzo

gianluigi.zangaridelbalzo@gmail.com

1 Sapienza University of Rome, Rome, Italy
2020 by the climate change scientist Antonello Pasini at the Italian National Research Council -CNR where it was speculated on a (impossible) cause-effect relationship between climate change and SARS-CoV-2 infection Pasini A and Italian National Research Council -CNR (2020).

So, both the WWF report and the CNR video discussed an impossible correlation between environment damage and impact (pollution, climate change) and the COVID19 pandemic. In any case, the topic immediately aroused my interest as a theoretical physicist and since the end of February 2020, I was wondering how the SARS-CoV-2 new coronavirus could be directly affected by the environment and what effects this correlation could have on the COVID-19 pandemic.

The first step was therefore to study the thermodynamics of the new coronavirus virus in the environment.

The next step was to keep in mind that in the study of the thermodynamics of the new coronavirus SARS-CoV-2 in air, the presence of pollen, bacteria, other viruses, spores, dust, but more particularly, that of nanoparticles of health interest at the same scale threshold as the spike proteins of 
the pandemic virus, such as particulate matter, cannot be neglected.

This also applies to simulations and biologic computational models. Otherwise, we run into serious systematic errors.

The result of these observations was the theory of the energy landscape proposed here.

At the beginning of March 2020 I published my work as a preprint, wishing to immediately make my observations available to the community of colleagues, operators in the sector, doctors, journalists and social networkers and at the same time sent to the authorities of the Italian Government.

Now, after a year, I am truly happy and grateful to the many colleagues and research institutes who have found useful my methodological notes. See the position paper of the Italian Society of Environmental Medicine (SIMA) issued on March 16, 2020 and a survey conducted in the USA by the Harvard School of Public Health Wu, X., Nethery, RC, Sabath, MB, Braun, D. and Dominici, F. (2020). They really went beyond the scope of my work as they speculated on a correlation between air pollution and infection, according to which the areas most affected by the infection were also the most polluted. But our paper is not concerned with this. We just proposed some methodological notes which lead us to the formulation of a general mathematical apparatus, suitable to explain at the molecular level the energetic configurations of the quasispecies of the pandemic virus SARS-CoV-2 in its environment. We focus complexes between the viral particle and other objects in its environment, at the scale threshold of the spikes of the viral particle, which can be dangerous to human health, as particulate matter. Then, we wondered if such complexes can lead to the generation of more aggressive viral variants and how to predict their populations and energy configurations, in order to plan an adequate prophylaxis.

\section{China and Italy}

Let's start on China and Italy the two nations tragically hit first by the epidemic. In the Chinese case, I will focus on Wuhan, the capital of Hubei Province, while in the Italian case I will focus on Northern Italy, with particular attention to the case of Lombardia. As an example, Lombardia has roughly the same population of Wuhan (about 10 million people) (The Government of Wuhan 2020; Setti et al. 2020; Regione Lombardia 2020). Both have been affected by the pandemic in the most devastating way. Both have suffered a severe environmental pollution situation in recent years, China with greater severity and impact on the health of population (Wang et al. 2019; CHINA National Environmental Monitoring Centre-CNEMC 2020; Rongshan Wu et al. 2018; Rohde and Muller 2015; He et al. 2017; Liang et al. 2019; Zhao et al. 2018; Liu et al. 2017; Anenberg et al. 2019; Zhu et al. 2018; Kuerban et al. 2020; Zhang and Cao 2015; Xu et al. 2020; Ren et al. 2017). Most papers analyze data from Chinese government agencies, as Wang et al. (2019), which refers to the Chinese Ministry of the Environment and Ecology, where we find the latest (2017) report of Ecology Ministry of Ecology of the People's Republic of China (2017) translated in English (See Figs. 1 and 2).

The Italian situation is summarized by the European Environment Agency [See Fig. 3 and 4 European Environment Agency (2019-2020)].
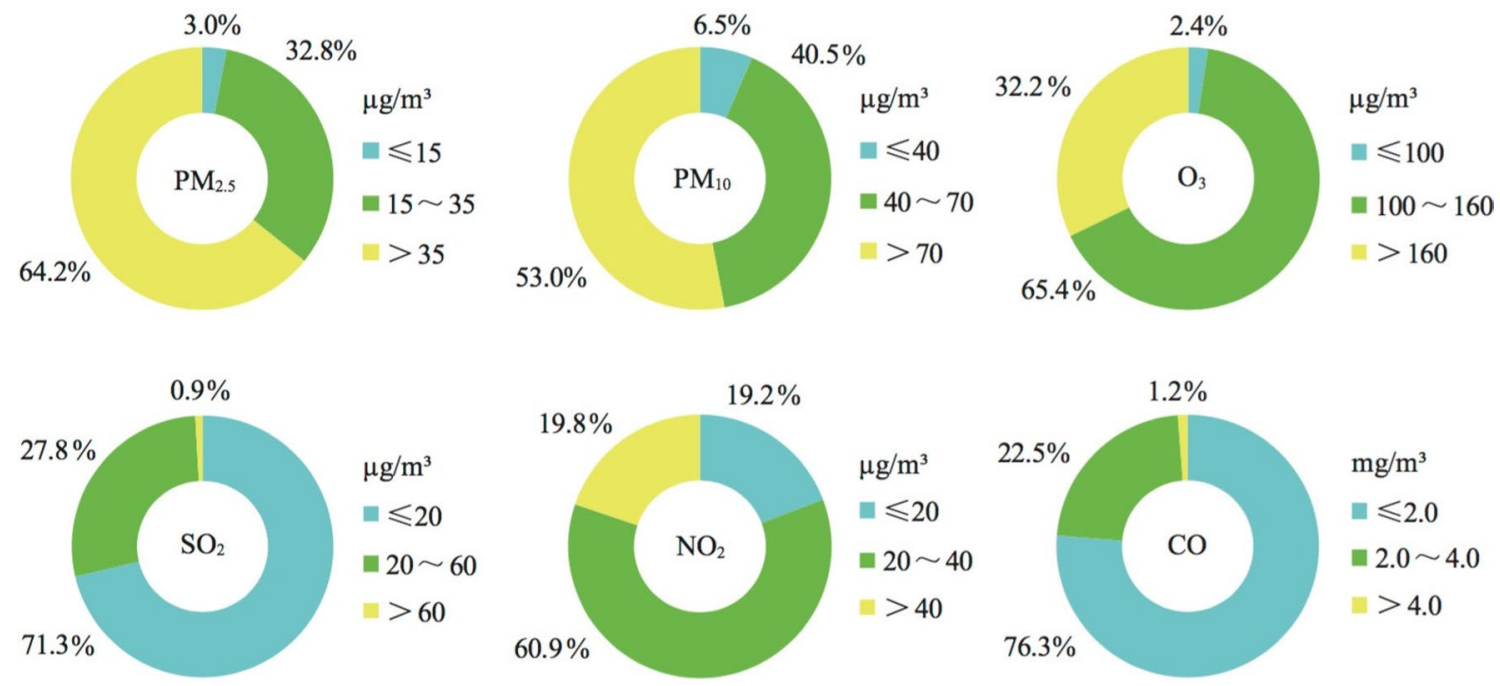

$\mathrm{mg} / \mathrm{m}^{3}$

$-\leqslant 2.0$

$\because 2.0 \sim 4.0$

$>4.0$

Fig. 1 Percentage of 338 Chinese cities with different concentrations of six major pollutants in 2017 [courtesy of the Chinese Ministry of the Environment and Ecology of Ecology and of the People's Republic of China (2017)]. Note the high percentage values of $\mathrm{PM}_{10}$ and $\mathrm{PM}_{2.5}$ 
Fig. 2 Air quality comprehensive index and primary pollutants of 74 Cities in 2017 [courtesy of the Chinese Ministry of the Environment and Ecology of Ecology and of the People's Republic of China (2017)]. Note the preponderance of $\mathrm{PM}_{2.5}$ among the primary pollutants, also for the city of Wuhan

\begin{tabular}{|c|c|c|c|c|c|c|c|c|c|}
\hline No. & City & $\begin{array}{c}\text { Compre- } \\
\text { hensive } \\
\text { index }\end{array}$ & $\begin{array}{c}\text { Maximum } \\
\text { index }\end{array}$ & $\begin{array}{l}\text { Primary } \\
\text { pollutant }\end{array}$ & No. & City & $\begin{array}{l}\text { Compre- } \\
\text { hensive } \\
\text { index }\end{array}$ & $\begin{array}{c}\text { Maximum } \\
\text { index }\end{array}$ & $\begin{array}{l}\text { Primary } \\
\text { pollutant }\end{array}$ \\
\hline 1 & Haikou & 2. 49 & 0.79 & $\mathrm{O}_{3}$ & 38 & Hangzhou & 5.02 & 1.29 & $\mathrm{PM}_{2.5}$ \\
\hline 2 & Lhasa & 3. 13 & 0.80 & $\mathrm{O}_{3}$ & 39 & Chongqing & 5.04 & 1. 29 & $\mathrm{PM}_{2.5}$ \\
\hline 3 & Zhoushan & 3.18 & 0.95 & $\mathrm{O}_{3}$ & 40 & Xining & 5.11 & 1. 19 & $\mathrm{PM}_{10}$ \\
\hline 4 & Xiamen & 3.37 & 0.80 & $\mathrm{NO}_{2}$ & 41 & Nanjing & 5.18 & 1. 18 & $\mathrm{NO}_{2}$ \\
\hline 5 & Fuzhou & 3. 42 & 0.88 & $\mathrm{O}_{3}$ & 42 & Huai'an & 5.18 & 1.43 & $\mathrm{PM}_{2.5}$ \\
\hline 6 & Huizhou & 3. 48 & 0.89 & $\mathrm{O}_{3}$ & 43 & Taizhou & 5.22 & 1.46 & $\mathrm{PM}_{2.5}$ \\
\hline 7 & Shenzhen & 3. 49 & 0.92 & $0_{3}$ & 44 & Changchun & 5.22 & 1. 31 & $\mathrm{PM}_{2.5}$ \\
\hline 8 & Lishui & 3. 54 & 0.94 & $\mathrm{PM}_{2.5}$ & 45 & Wuxi & 5.28 & 1.26 & $\mathrm{PM}_{2.5}$ \\
\hline 9 & Guiyang & 3.61 & 0.91 & $\mathrm{PM}_{2.5}$ & 46 & Suqian & 5.34 & 1.57 & $\mathrm{PM}_{2.5}$ \\
\hline 10 & Zhuhai & 3. 64 & 1.00 & $\mathrm{O}_{3}$ & 47 & Changzhou & 5.41 & 1. 37 & $\mathrm{PM}_{2.5}$ \\
\hline 11 & Taizhou & 3.65 & 0.94 & $\mathrm{PM}_{2.5}$ & 48 & Wuhan & 5. 46 & 1. 49 & $\mathrm{PM}_{2.5}$ \\
\hline 12 & Kunming & 3. 76 & 0.83 & $\mathrm{PM}_{10}$ & 49 & Zhenjiang & 5.63 & 1. 57 & $\mathrm{PM}_{2.5}$ \\
\hline 13 & Nanning & 3.95 & 1.00 & $\mathrm{PM}_{2.5}$ & 50 & Hefei & 5.65 & 1. 60 & $\mathrm{PM}_{2,5}$ \\
\hline 14 & Dalian & 4. 15 & 1.02 & $\mathrm{O}_{3}$ & 51 & Harbin & 5.71 & 1.66 & $\mathrm{PM}_{2,5}$ \\
\hline 15 & Zhongshan & 4. 16 & 1.13 & $\mathrm{O}_{3}$ & 52 & Yangzhou & 5.72 & 1.54 & $\mathrm{PM}_{2.5}$ \\
\hline 16 & Zhang jiakou & 4. 18 & 1.08 & $\mathrm{O}_{3}$ & 53 & Shenyang & 5.78 & 1. 43 & $\mathrm{PM}_{2.5}$ \\
\hline 17 & Ningbo & 4. 31 & 1.06 & $\mathrm{PM}_{2.5}$ & 54 & Chengdu & 5.85 & 1.60 & $\mathrm{PM}_{2.5}$ \\
\hline 18 & Quzhou & 4. 37 & 1.20 & $\mathrm{PM}_{2.5}$ & 55 & Qinhuangdao & 5.86 & 1.26 & $\mathrm{PM}_{2.5}$ \\
\hline 19 & Dongguan & 4. 37 & 1.06 & $\mathrm{O}_{3}, \mathrm{PM}_{2.5}$ & 56 & Bei jing & 5.87 & 1.66 & $\mathrm{PM}_{2.5}$ \\
\hline 20 & Wenzhou & 4. 40 & 1.09 & $\mathrm{PM}_{2.5}$ & 57 & Hohhot & 5.93 & 1.36 & $\mathrm{PM}_{10}$ \\
\hline 21 & Jinhua & 4. 44 & 1.20 & $\mathrm{PM}_{2.5}$ & 58 & Yinchuan & 6.41 & 1.51 & $\mathrm{PM}_{10}$ \\
\hline 22 & Zhaoqing & 4. 47 & 1.17 & $\mathrm{PM}_{2.5}$ & 59 & Lanzhou & 6.45 & 1.59 & $\mathrm{PM}_{10}$ \\
\hline 23 & Yancheng & 4. 58 & 1.23 & $\mathrm{PM}_{2.5}$ & 60 & Tianjin & 6.53 & 1. 77 & $\mathrm{PM}_{2.5}$ \\
\hline 24 & Jiangmen & 4.60 & 1.21 & $\mathrm{O}_{3}$ & 61 & Urumchi & 6.55 & 2. 00 & $\mathrm{PM}_{2.5}$ \\
\hline 25 & Guangzhou & 4.61 & 1.30 & $\mathrm{NO}_{2}$ & 62 & Langfang & 6.61 & 1.71 & $\mathrm{PM}_{2.5}$ \\
\hline 26 & Shanghai & 4. 63 & 1.13 & $\mathrm{O}_{3}$ & 63 & Xuzhou & 6.78 & 1.94 & $\mathrm{PM}_{2.5}$ \\
\hline 27 & Jiaxing & 4. 72 & 1.20 & $\mathrm{PM}_{2.5}$ & 64 & Cangzhou & 6.89 & 1. 89 & $\mathrm{PM}_{2.5}$ \\
\hline 28 & Shaoxing & 4. 73 & 1.29 & $\mathrm{PM}_{2.5}$ & 65 & Jinan & 7.04 & 1.86 & $\mathrm{PM}_{2.5}$ \\
\hline 29 & Foshan & 4. 75 & 1. 14 & $\mathrm{PM}_{2,5}$ & 66 & Zhengzhou & 7.07 & 1.89 & $\mathrm{PM}_{2.5}$ \\
\hline 30 & Nanchang & 4.75 & 1.17 & $\mathrm{PM}_{2.5}$ & 67 & Hengshui & 7.29 & 2.20 & $\mathrm{PM}_{2.5}$ \\
\hline 31 & Qingdao & 4. 78 & 1.11 & $\mathrm{PM}_{10}, \mathrm{PM}_{2.5}$ & 68 & Xi' an & 7.72 & 2. 17 & $\mathrm{PM}_{2.5}$ \\
\hline 32 & Lianyungang & 4. 79 & 1.29 & $\mathrm{PM}_{2.5}$ & 69 & TaiYuan & 7. 79 & 1. 89 & $\mathrm{PM}_{2.5}$ \\
\hline 32 & Nantong & 4. 79 & 1.12 & $\mathrm{O}_{3}$ & 70 & Tangshan & 7.97 & 1.89 & $\mathrm{PM}_{2.5}$ \\
\hline 34 & Huzhou & 4. 80 & 1. 20 & $\mathrm{PM}_{2.5}$ & 71 & Baoding & 8.32 & 2. 40 & $\mathrm{PM}_{2.5}$ \\
\hline 35 & Chengde & 4. 86 & 1. 17 & $\mathrm{PM}_{10}$ & 72 & Xingtai & 8.57 & 2. 29 & $\mathrm{PM}_{2.5}$ \\
\hline 36 & Suzhou & 4. 97 & 1.20 & $\mathrm{NO}_{2} 、 \mathrm{PM}_{2.5}$ & 73 & Handan & 8.64 & 2. 46 & $\mathrm{PM}_{2.5}$ \\
\hline 37 & Changsha & 4. 98 & 1.49 & $\mathrm{PM}_{2.5}$ & 74 & Shi jiazhuang & 8.72 & 2. 46 & $\mathrm{PM}_{2.5}$ \\
\hline
\end{tabular}

Note that the highest values of particulate matter are reached in the regions of Northern Italy (See Fig. 4), (See Fig. 5).

\section{Particulate matter}

Among the particles of interest for human health at the scale threshold of the pandemic virus, we focus our study on particulate matter, whose damage to the human airways is well known and studied. The definition of particulate matter (hereinafter referred to as "PM") and its health effects are well-known. We recall the definition given by the U.S. Environmental Protection Agency (EPA) United States Environmental Protection Agency-EPA (2020): PM is a mixture of solid particles and liquid droplets in air.

We then have:

$\mathbf{P M}_{10}$ : particles, with diameters that are generally $10 \mu \mathrm{m}$ and smaller. 
Fig. 3 Italy-air pollution country fact sheet 2019 (courtesy of European Environment Agency 2019b)

\section{Air pollution country profile: Italy}

\section{Air quality}

The table below shows the percentage of urban population exposed to concentrations above EU standards for selected air pollutants such as $\mathrm{PM}_{10}$, $\mathrm{PM}_{2.5}, \mathrm{O}_{3}, \mathrm{NO}_{2}$ and $\mathrm{BaP}$ for the years 2012-2017.

\begin{tabular}{|c|c|c|c|c|c|c|}
\hline & & 2013 & 2014 & 2015 & 2016 & 2017 \\
\hline BaP & annual mean & 2,8 & 1,5 & 7,8 & 5,7 & 6,6 \\
\hline NO2 & annual mean & 27,5 & 15,7 & 27,9 & 23,2 & 23,8 \\
\hline 03 & percentile 93.15 & 52,0 & 25,6 & 72,5 & 45,4 & 62,9 \\
\hline PM10 & percentile 90.41 & 64,9 & 48,9 & 64,9 & 42,5 & 44,2 \\
\hline PM2.5 & annual mean & 72,0 & 27,0 & 78,3 & 59,2 & 75,0 \\
\hline
\end{tabular}

The PM10 percentile 90.41 concentrations in 2017 in Italy compared to the EU daily limit value $(50 \mathrm{\mu g} / \mathrm{m} 3)$

The trend of PM10 percentile 90.41 concentrations in Italy compared to the EU daily limit value [50 $\mathrm{\mu g} / \mathrm{m} 3)]$
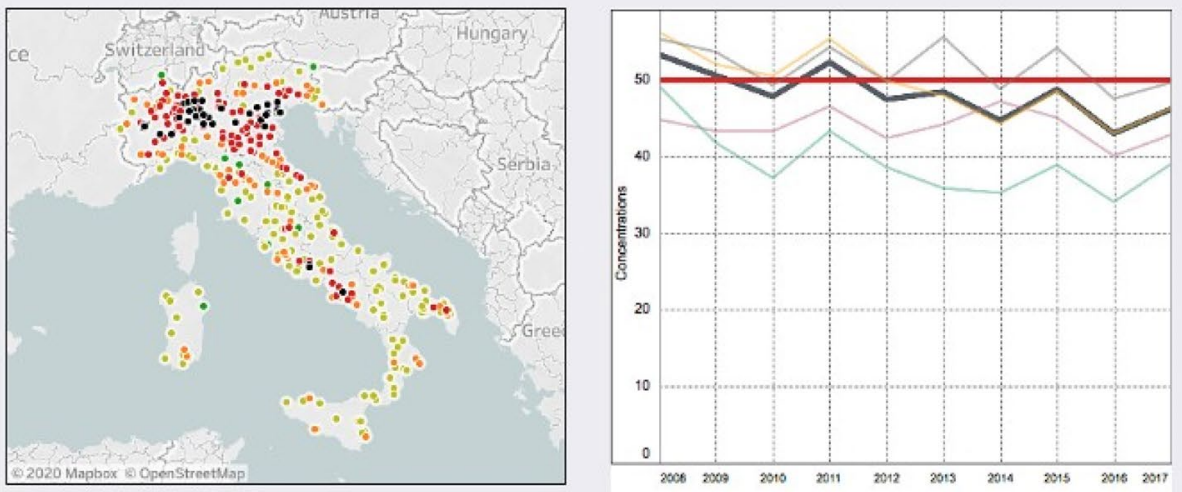

CPM10: $75.0-\mu \mathrm{gim} 3$.

PIM10: $50.0-75.0 \mathrm{ug} / \mathrm{m}^{3}$.

PMA10 : $40.0-50.0 \mathrm{~kg} / \mathrm{m}^{2}$

- РM10: $20.0-40.0$ ע0m3

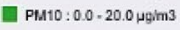

Area and station type

Area and station type stations

Theshold background nural

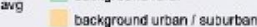

other or unknown

\begin{tabular}{|c|c|c|c|c|c|c|c|}
\hline \multicolumn{8}{|c|}{ unknown } \\
\hline & & 2013 & 2014 & & 2015 & 2016 & 2017 \\
\hline BaP & annual mean & 2,8 & 1,5 & & 7,8 & 5,7 & 6,6 \\
\hline NO2 & annual mean & 27,5 & 15,7 & & 27,9 & 23,2 & 23,8 \\
\hline 03 & percentile 93.15 & 52,0 & 25,6 & & 72,5 & 45,4 & 62,9 \\
\hline PM10 & percentile 90.41 & 64,9 & 48,9 & & 64,9 & 42,5 & 44,2 \\
\hline PM2.5 & annual mean & 72,0 & 27,0 & & 78,3 & 59,2 & 75,0 \\
\hline Country & $\begin{array}{l}\text { Population } \\
(\mathbf{x} 1000)\end{array}$ & $\begin{array}{l}\text { nean } \\
\text { 5) }\end{array}$ & $\begin{array}{c}\text { Premature } \\
\text { deaths } \\
\text { (PM2.5) }\end{array}$ & $\begin{array}{l}\text { Innual mean } \\
\text { (NO2) }\end{array}$ & $\begin{array}{r}\text { Sor } \\
\text { Pre } \\
\text { deat }\end{array}$ & Somo35 (03) & $\begin{array}{l}\text { Somma di } \\
\text { Premature } \\
\text { deaths (03) }\end{array}$ \\
\hline
\end{tabular}

\begin{tabular}{|c|c|c|c|c|c|c|c|}
\hline Italy & 60.666 & 16,6 & 58.600 & 22,1 & 14.600 & 6.058 & 3.000 \\
\hline EU-28 & 506.028 & 12,93 & 374.000 & 16,29 & 68.000 & $3.547,19$ & 14.000 \\
\hline Italy & 60.666 & 16,63 & 58.600 & 22,09 & 14,600 & $6.057,78$ & 3.000 \\
\hline Total & 538.014 & 14.42 & 412.000 & 16.28 & 71.000 & $3.811,00$ & 15.100 \\
\hline
\end{tabular}




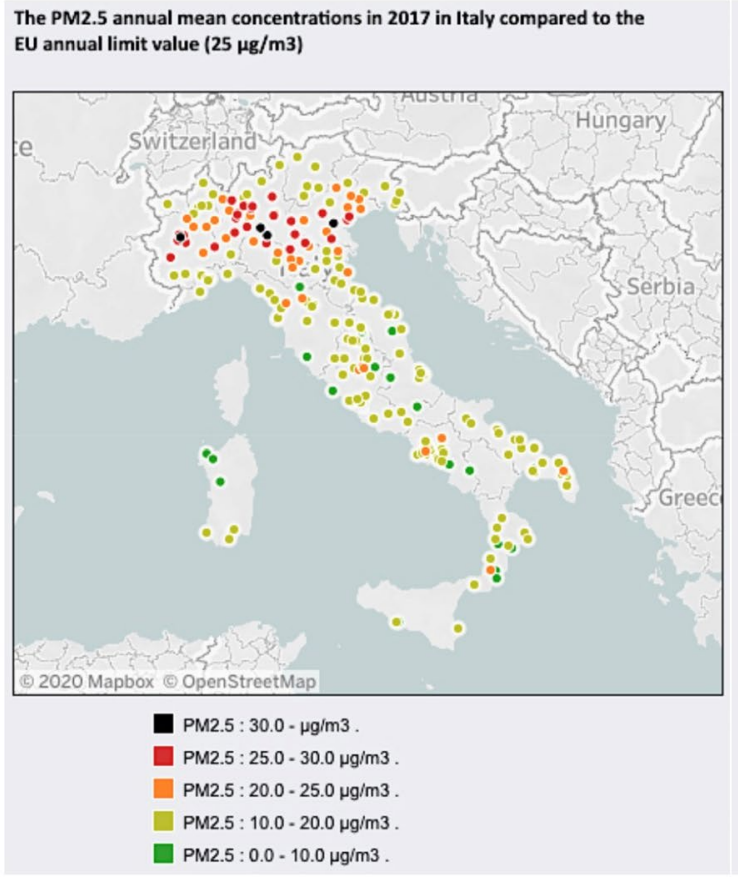

The PM10 percentile 90.41 concentrations in 2017 in Italy compared to the EU daily limit value $(50 \mathrm{\mu g} / \mathrm{m} 3)$

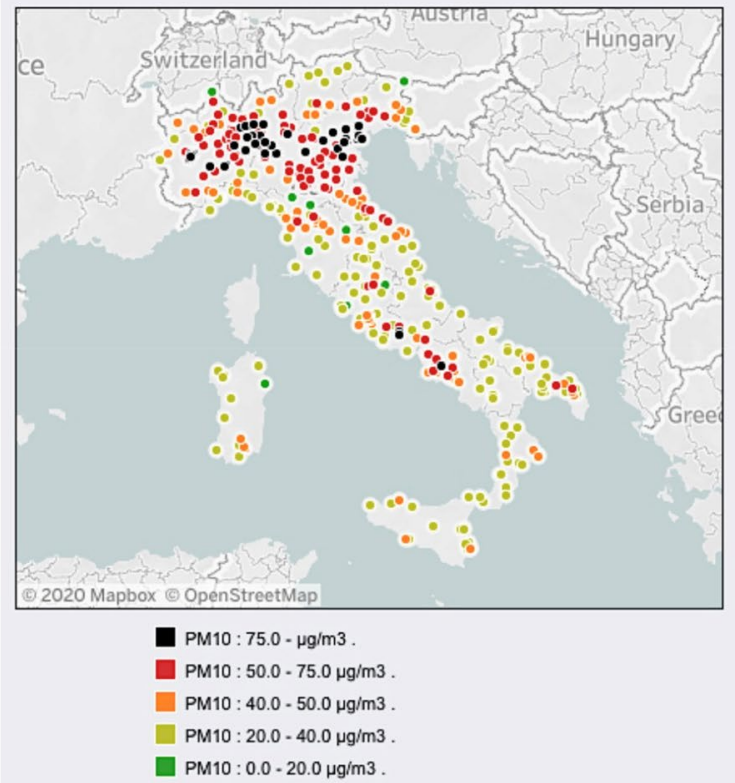

Fig. 4 The PM2.5 annual mean concentrations in 2017 in Italy compared to the EU annual limit value $\left(25 \mu \mathrm{g} / \mathrm{m}^{3}\right)$ (Left) The PM10 percentile 90.41 concentrations in 2017 in Italy compared to the EU daily limit value $\left(50 \mu \mathrm{g} / \mathrm{m}^{3}\right)$ (Right). Note that the highest values of

$\mathbf{P M}_{2.5}$ : fine particles, with diameters that are generally $2.5 \mu \mathrm{m}$ and smaller.

Ultrafine particulate (UFPs) are defined as "respirable dust," that is, capable of penetrating deeply into the lungs and undergo interstitialization, Friedlander et al. (2003)

We then have:

$\mathbf{P M}_{1}$, with a diameter of less than $1 \mu \mathrm{m}$;

$\mathbf{P M}_{0.1}$, with a diameter of less than $0.1 \mu \mathrm{m}$.

The health effects of PM are devastating, particularly in the lungs. $\mathrm{PM}_{2.5}$ is a thoracic powder capable of penetrating deeply into the lungs during breathing, while the ultrafine particulate matter (UFPs) is in all respects a "respirable dust," which settles in the lungs, where the nanoparticles have the ability to penetrate the tissues and undergo interstitialization or to be absorbed directly into the bloodstream (Friedlander et al. 2003; Scientific Committee on Emerging and Newly Identified Health Risks-SCENIHR 2006; Scientific Committee on Health and Environmental RisksSCHER 2005; European Environmental Agency (2019; Xing et al. 2016; MacNee et al. 2003). The studies on the damage caused by PM on the respiratory system generally take into account free radical peroxidation, imbalanced calcium homeostasis, inflammatory lesions, etc. In particular, the peroxidation of free radicals is one of the main factors
Particulate Matter are reached in the regions of Northern Italy, particularly for PM 2.5. Courtesy of the European Environment Agency (2019b)

causing oxidative DNA damage. Indeed, when damaged DNA is not repaired effectively over time, it can induce carcinogenesis, mutagenesis, and other irreversible damage (SCHER 2005; European Environment Agency 2019; Xing et al. 2016; MacNee et al. 2003). Moreover, oxidative stress within cells is an additional factor leading to transcription of pro-inflammatory genes (Xing et al. 2016; MacNee et al. 2003).

\section{SARS-CoV-2}

SARS-CoV-2 virus is a beta-coronavirus as SARS-CoV; its RNA genome is about $82 \%$ identical to the SARS-CoV (Zhang et al. 2020). SARS-CoV-2 has round or elliptic and often pleomorphic form, and a diameter of circa 60-140 nm (Cascella et al. 2020). Angiotensin converting enzyme 2 (ACE2) is the cell receptor for both the SARS-CoV and the new SARS-CoV-2 (Yan et al. 2020). Now, we know the $\mathrm{X}$-ray structures of the unliganded SARS-CoV-2 $\mathrm{M}^{\text {pro }}$ and its complex with an $\alpha$-ketoamide inhibitor (Zhang et al. 2020) and many other features. As virus SARS-CoV, the new virus SARS-CoV-2 also enters cells through an endocytic pathway (Hongliang Wang et al. 2008), as has recently been confirmed by many studies such as an interesting "snapshot" of COVID-19 by Blake Oberfield et al. (Harvard Medical 
Fig. 5 Contagion maps in Italy. Top left-situation on 25 April 2020. Top right-situation on 12 June 2020 — center situation update March 11, 2021 [courtesy of Corriere della Sera della Sera (2021)]. If we compare these maps with the previous Fig. 4, we immediately notice that the areas most affected by the pandemic are the most polluted. Here, we find the same type of correlation studied by T.H. Chan School of Public Health at Harvard Wu et al. (2020)

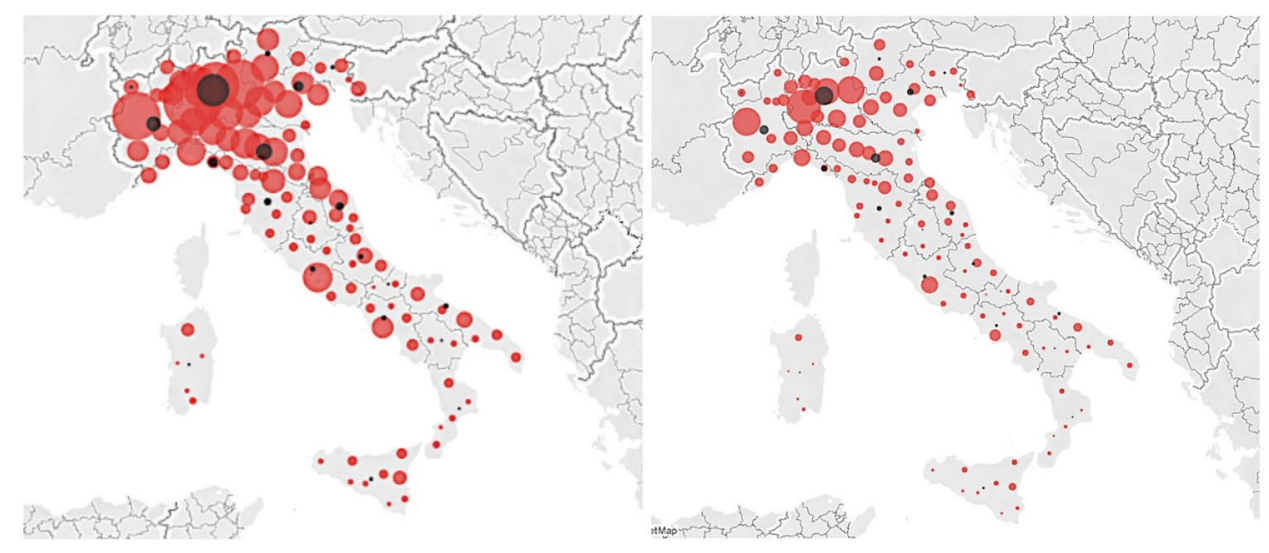

LA DIFFUSIONE GEOGRAFICA DEL VIRUS

I contagi in Italia per regione I contagi in Italia per provincia

I contagi in Italia per regione

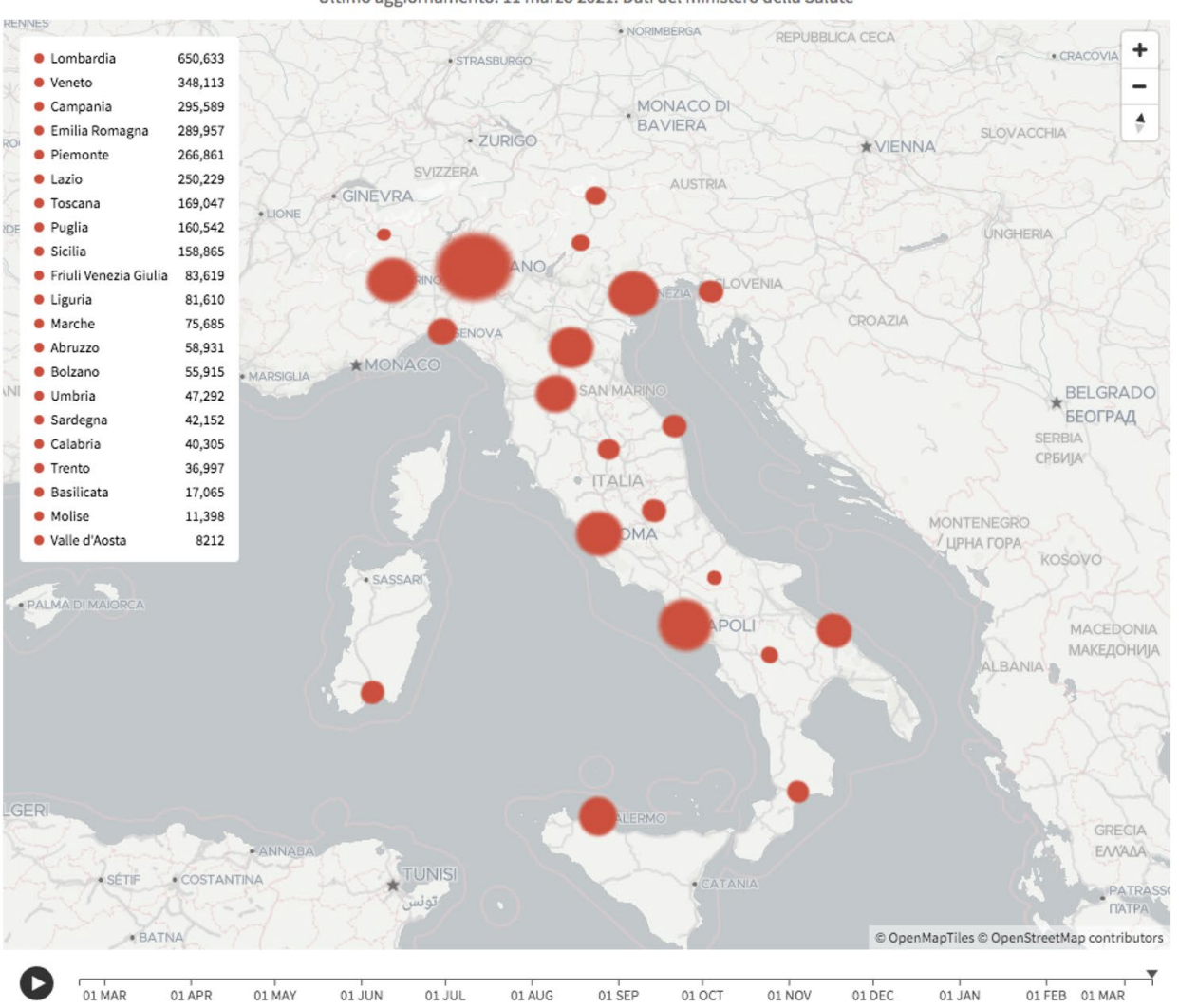

School and MIT) (Oberfield et al. 2020), by Alexandra C. Walls et Al. (Washington University, Seattle, USA), Walls et al. (2020) and many others. With each passing day, new details emerge. Very recently (March, 2021), Wendy S. Barclay of Imperial College London hypothesized that new variants of the pandemic coronavirus such as the "Delta" variant, could specialize in an endosome-independent entry, exploiting a selective advantage in primary human airway epithelial cells, resulting from a higher differential expression of the cell surface protease TMPRSS2 (Peacock et al. 2021). But we will have to wait to know if the variants of the pandemic virus that specialize in endosome-independent entry are also expressed in the human population and, in this case, what will be their percentage ratio with respect to the viral species that follow the endocytic pathways. Furthermore we will have to study in detail the structure of SARS-CoV-2 spike proteins to understand what is the interaction of the spike with the nanoparticles of the environment and if this 
(a)

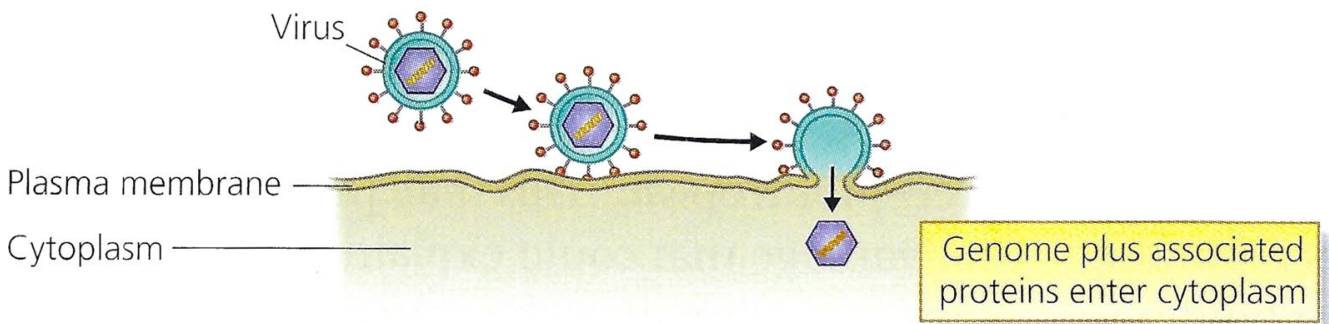

(b)

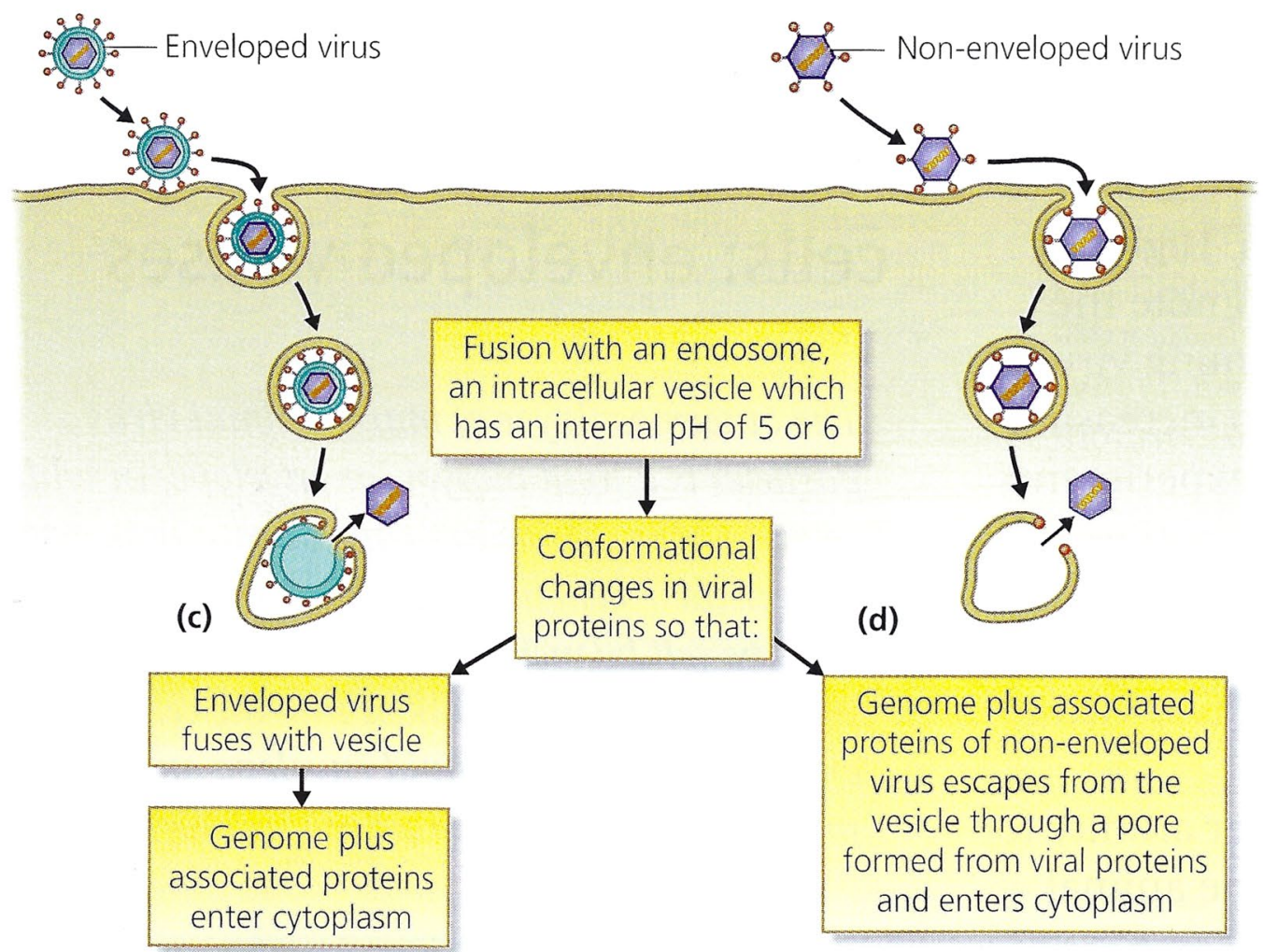

(e)

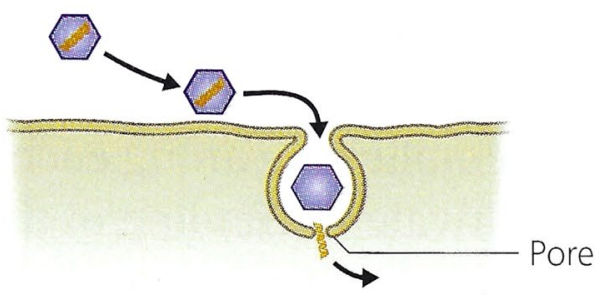

Fig. 6 Entry of animal virus genomes into cells [courtesy of NJ Dimmock et al. Dimmock et al. (2016)]

interaction can somehow influence and impact the cleavage sites of the protein and other crucial sites suitable to mediate host's cell entry. Another interesting topic concerns the role of glycans, which camouflage the spikes, making the viral particles "stealth" for the host's immune system. What are the interactions of glycans with particles and other objects in the environment? And beyond. Can nanoparticles of the environment at the same scale as spikes have the same "stealth" effect as glycans? Can they hide the pandemic virus from the immune system? We underline that the methodological observations carried out, also concern the studies that speculate on the endosome-independent cell entry, because they are affected by the same systematic errors already discussed. This confirms, in case there were still any doubts, 
the urgency to tackle the methodological problem once and for all. We will return to this fundamental topic soon. We acknowledge the excellent actions promoted by CERN community such as "CERN against Covid-19" CERN, Genève, CH (2020a), "Zenodo" (Open Science against COVID-19, which I also adhere to) CERN, Genève, CH (2020c), and the platform folding@home, which is a distributed computing project for simulating the dynamics of protein molecules CERN, Genève, CH (2020b).

Finally, I remember the very updated report of the Covid19 Commission of the Accademia Nazionale dei Lincei, directed by Prof. Giorgio Parisi Accademia Nazionale dei Lincei (2021).

In the following figure, courtesy of Dimmock et al. (2016), we recall the main processes of entry of animal viruses genomes into cells (Fig. 6).

In the present case, SARS-CoV-2 will exploit the process (b) of the previous Fig. 5 (receptor-mediated endocytosis), apart from the recent speculations of Wendy S. Barclay of Imperial College London concerning endosome-independent cell entry pathways of new variants of the pandemic virus (see above), which, however, has yet to be found and verified in the human population. Thus, SARS-CoV-2 is an enveloped virus that enters the cell in a vesicle (endocytosis). The vesicle subsequently merges with an endosome. The low $\mathrm{pH}$ environment inside the endosome promotes conformational changes in viral proteins that lead to the fusion of the lipid bilayer of the virus with the endosome allowing the viral genome and its associated proteins to enter the cytoplasm.

This is the big picture. However, in our case, things are a bit more bizarre and require a more advanced formalism.

\section{SARS-CoV-2 and particulate matter}

The generally accepted description of endocytosis, which we also find in the text by Dimmock et al. (2016) is wrong because nothing is specified about the environment, as if a viral particle could exist without its environment. Living matter cannot exist in a vacuum. Even more so the pandemic virus, given that it is an obligate parasite. Therefore it cannot exist in se ipsum. We are thus facing a complete violation, both logic and functional of the scientific method, that
Fig. 7 Snapshot of a simulation of a SARS-CoV-2 ball with its environment for a low density UFP particulate dust from 0.025 to $0.100 \mu \mathrm{m}$

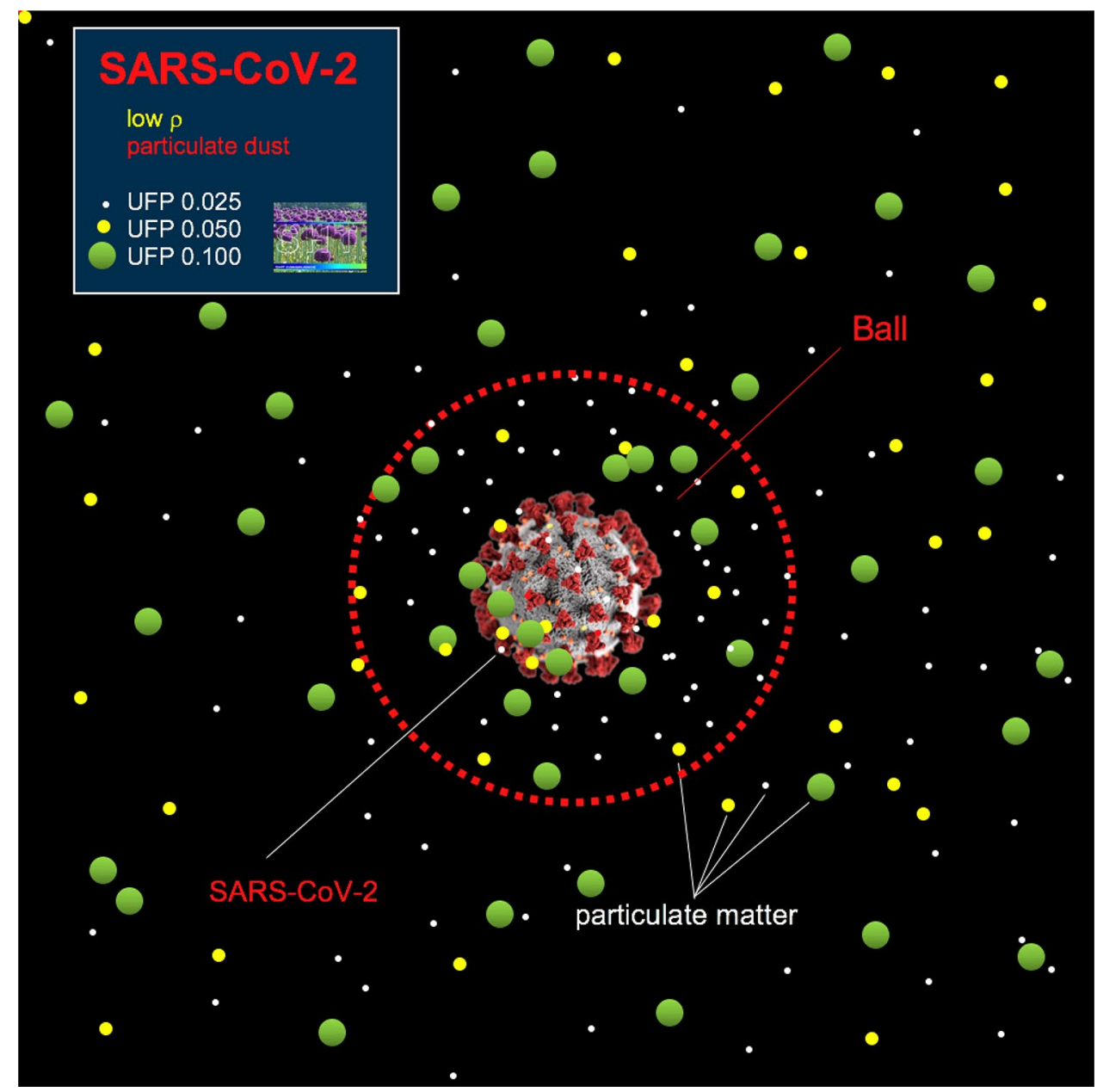




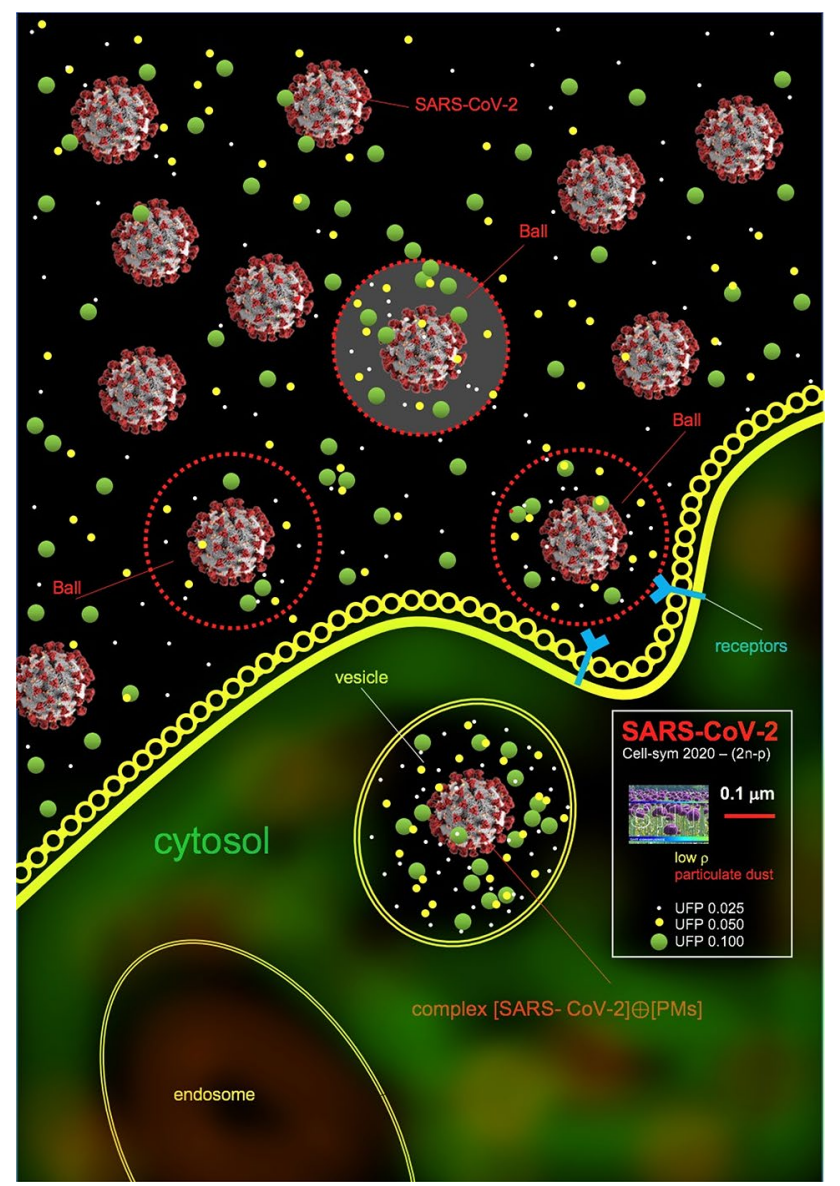

Fig. 8 Snapshot of a simulation of the endocytosis of SARS-CoV-2 with its environment (ball) low density-UFP particulate dust $0.025 \mu \mathrm{m}, 0.050 \mu \mathrm{m}$ and $-0.100 \mu \mathrm{m}$ is involving a violations of the conditions of necessity and sufficiency. Remembering Bertrand Russell (1870-1970) and Karl Popper (1902, 1994), we can say that a theory or a model of living matter in a vacuum, leads to a nonsense, whose formal degradation is comparable with the brocardo "nihil sine causa datum est"; which precipitates the theory (and the experiment that employs it) into a reductio ad absurdum. At this purpose, the present author is working on the so-called Russell categories or "Russellians", defined to avoid these methodological nonsenses. Moreover, we noted that the same nonsense is achieved with mathematical simulations of both the background and the environment, offered by commercial software (sold with the equipment), and by taylor-made computational biology algorithms. Just on a computational level, this logical and methodological nonsense is a "blue error", that is, a major school error, which becomes a serious systematic error that hits the statistics of an experiment to death.

So let's begin our study of the pandemic virus in its air environment.

Consider a given concentration of viral particles per unit of air volume. As an example, among the many works, including Italian ones, we choose a recent paper by a Wuhan doctor, Liu et. al. (2020), about the concentration of different aerodynamic dimensions of SARS-CoV-2 aerosols in Wuhan hospitals during the lockdown, so as not to overestimate the concentrations.

Consider thus a spherical neighborhood (ball) $\mathcal{B}(r)$ of radius $r>0$ around a viral particle such that $r_{0}<r<\mathrm{pr}_{0}$ where $r_{0}$ is the average diameter of a viral particle and $p=1, \ldots, L \in N$, where $L$ is the side of a cubic box with a
Fig. 9 SARS-CoV-2 with its environment inside a vesicle, as an isolated thermodynamic system. Universe (SARS-CoV-2 with its environment) and the rest of the universe (environment). Low UFP dust 0.025 $0.100 \mu \mathrm{m}$

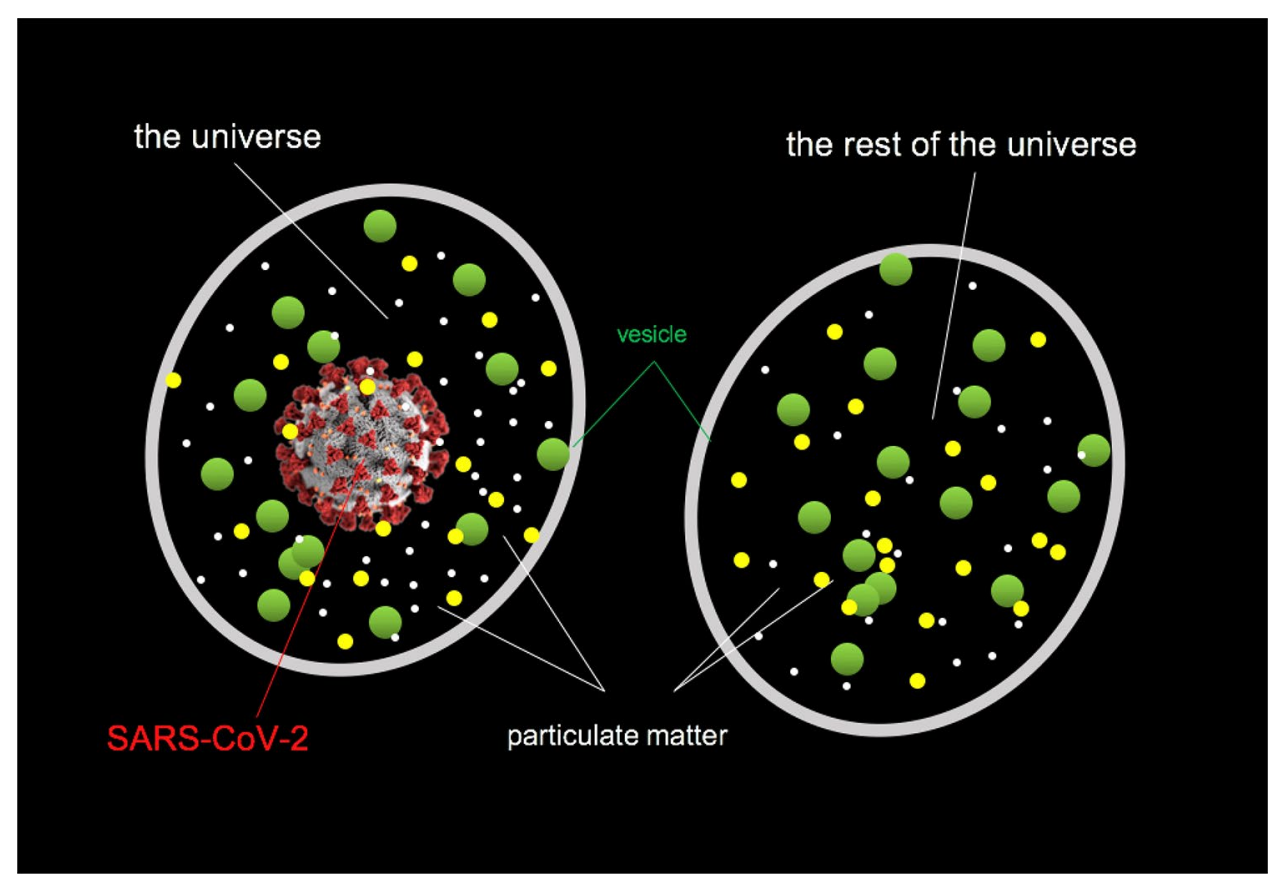


volume of $1 \mu \mathrm{m}^{3}$. For each $p>0$, there will be a ball $\mathcal{B}(r)$ in which a number $N \neq 0$ of PM (particulate matter) particles will fall.

The following Fig. 7 shows a snapshot of a possible scenario of the ball (SARS-CoV-2 with the environment) for a low density of the UFP dust from 0.025 to $0.100 \mu \mathrm{m}$.

As shown in Fig. 8 below, the endocytosis process captures the entire ball containing the virus with its micro-environment inside a vesicle, deforming the ball shape into an "ellipsoid" (see Fig. 8).

From the moment the endocytosis process takes place and the whole ball is incorporated into the vesicle, a thermodynamic isolated system is created inside the vesicle (See Fig. 9).

\section{A synergistic cooperation between SARS-CoV-2 and particulate matter}

We see below how important it is to consider and study the environment where the pandemic virus combines with the host. Conversely, neglect of the environment leads to nonsenses and serious systematic errors throughout the pandemic COVID-19 research chain, as we said earlier.

Consider that the new coronavirus SARS-CoV-2 is an obligate parasite and our species is its host, that is, the virus needs us to be able to replicate itself.

Let's focus on the parasite's attack strategies in its hunting environment, where the host lives.

The adaptation of the parasite to the host's environment conditions its attack strategy also at the molecular level. The global spread of the pandemic virus SARS-CoV-2 tells us that the parasite specialized in exploiting to its own advantage the environment. At this point, recall that the atmospheric environment is not an empty box as is currently modeled, but it contains a huge amount of items, pollen, bacteria, other viruses, spores, dust, but more particularly, that of nanoparticles of health interest at the same scale threshold of the spike proteins of the pandemic virus, as particulate matter. An important point to emphasize is that none of these objects should and can be overlooked, because each component of the environment is not additive, but has a non-linear dependence between the other components and the pandemic virus, being the environment in the presence of the virus (i.e. the thermodynamic universe) a complex system that cannot be reduced.

To get an idea of how the parasite specialized in exploiting the host's environment to its advantage, let's consider a case belonging to human technology. This example can help us to have a qualitative and quantitative idea of the dynamics we are trying to understand.

Much human research on nanotechnologies has sought to exploit the ability of certain compounds such as mesoporous silica nanomaterials (MSNs) to penetrate human cells through endocytosis, to perform intracellular detection and monitoring functions or to release genetic material or drugs inside of the cell Trewyn et al. (2008).

As we will see, this is precisely the behavioral strategy that we expect from the interaction of the pandemic virus with the objects in the environment. Among the set of competitive processes that the pandemic virus can carry out by exploiting the environment, the one that has the greatest selective advantage, as we will demonstrate shortly, is the process of endocytosis through nanoparticles. Likewise, in the host's environment, at the threshold scale of the spikes, particulate matter is, as we have seen, the one that has the most devastating impact on health. Consider therefore the effect of nanoparticles of particulate matter, which we indicate as "PM" (See Fig. 8). Endocytosis through PM is performed by the parasite through a complex [SARS - CoV - 2] $\oplus[\mathrm{PM}]$, where we have chosen to indicate the equilibrium complex between the pandemic and PM with the operator symbol " $\oplus$ ". With this "direct sum" symbol we mean an equilibrium complex, where all the interactions between the components of the thermodynamic universe have stabilized. We will see shortly that this occurs inside a vesicle. Among these we consider an annihilation operator Aleph $\aleph=\aleph(Q)$ on a certain cell set la $>$, such that, for a certain element $K(Q)$ (belonging to the thermodynamic universe), the average destructive action against the cell set is maximum, per volume, sample, per unit of time. We will now see that $\mathrm{Q}$ is the order parameter of our model. That is $\langle\aleph\{[$ SARS-CoV-2] $\oplus[\mathrm{K}]\}\rangle$ is maximum if the $K(Q)$ component coincides with [PM], that is for $Q \approx 1$. We can take a $1 \mathrm{~mm}^{3}$ cubic sample of human lung or upper airway epithelial cells. Now we will see how this complex will work out and what its selective strength or advantage will be.

First, let's look at some characteristics that will be useful to us when we will deal with entropy of configurations. From the parasite's point of view, this strategy reveals intelligence, adaptability. Can we talk about intelligence for a virus? Maybe this is our best chance. While from the host's point of view, the [SARS-CoV-2] $\oplus[\mathrm{PM}]$ complex is a devastating weapon, not only because it introduces lethal poisons into cells, weakening the organism and irreparably damaging cellular structures and architectures (i.e., the pulmonary epithelial cells), but also because it exploits the ability of the particulate dust to promptly alter molecular structures and functions and induce genetic modifications. In the end, it is as if the host is being bombed by a "smart bomb.". From our point of view as researchers, this strategy expresses a strong selective advantage, therefore a necessity, vital for the obligate parasite, because it maximizes the reproductive efficacy of the viral species. Later we will develop a 


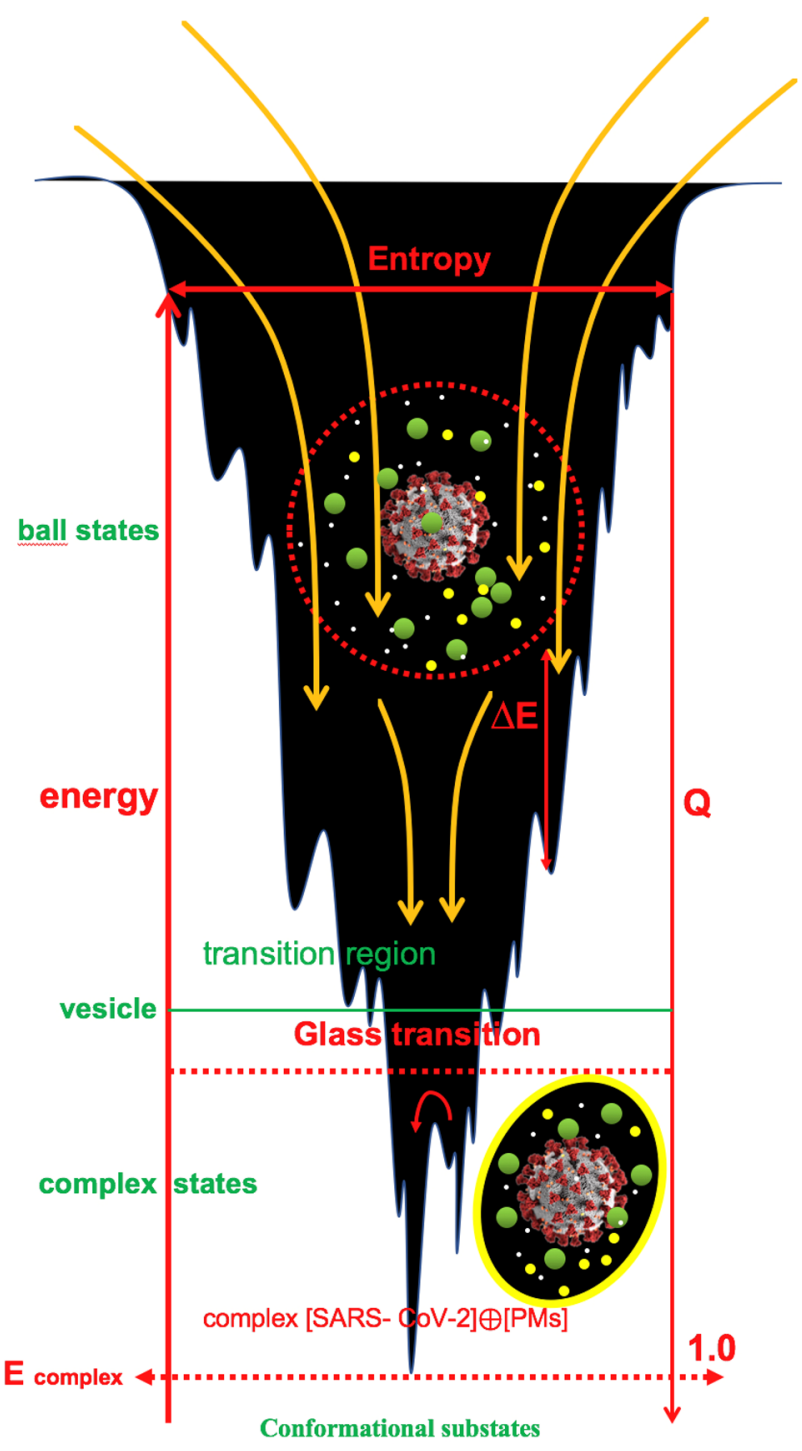

Fig. 10 Energy rugged funnel landscape for [SARS-CoV-2] $\oplus[\mathrm{PMs}]$ complex formation

formalism (the energy landscape) that will help us to express these concepts in mathematical language.

Our "smart bombs" are thus [SARS $-\mathrm{CoV}-2] \oplus[\mathrm{PM}]$ complexes entropy, close packed, highly cooperative and synergistic structures. As we will see, the dynamics leading to the formation of the complexes will be governed by a control parameter. In this way, the spikes of the new coronavirus will strictly interact with the particulate dust. Since the system is isolated inside a vesicle, that is the thermodynamic universe (See Fig. 9), all the interaction processes (mechanical-thermal-chemical) between the viral particle and the particulate dust will go to thermodynamic equilibrium, thus stabilizing the compound in a synergistic cooperative single entity, that is the complex.
For the perspective (and health) of the host, complexes [SARS $-\mathrm{CoV}-2] \oplus[\mathrm{PM}]$ thus achieve a synergistic and highly cooperative smart optimization of the cell demolition strategies, which exceed the individual potentials of both viral and particulate particles, as soon as they are considered as independent forcing agents on the host cell. With the previous formalism we can say that $\aleph\{[$ SARS-CoV-2] $\oplus[\mathrm{PM}]\}$ $\geq \aleph[$ SARS-CoV-2]+ $\aleph[\mathrm{PM}]$ per volume and sample, per unit of time

The presence of multiple non-covalent interactions between SARS-CoV-2 and PM is a source of cooperativity between them. When these interactions cooperate in the isolated system of the vesicle, a single stable conformation is created: a minimum entropy complex given by SARS-CoV-2 and PM: [SARS - CoV - 2] $\oplus[\mathrm{PM}]$. The complex created is therefore much stronger than might be expected from the sum of their individual strengths because we are dealing with complex systems.

Let's see from the theoretical point of view how the complex formation mechanism can be represented and described by a mathematical model.

\section{The energy landscape of [SARS-CoV-2] $\oplus$ [PMs] complexes}

The theoretical structure that is the most appropriate to describe the complexes [SARS $-\mathrm{CoV}-2] \oplus[\mathrm{PM}]$ is that of the "rugged funnel" energy landscape by Frauenfelder (2005), Frauenfelder et al. (1991), Frauenfelder (1997), Wolynes and Luthey-Schulten (1997).

Molecular biophysical interactions between viral particles and PM dust are mediated by SARS-CoV-2 proteins (e.g., spike proteins); therefore, the energy rugged funnel is certainly the best possible model.

\section{Postulate 1. Rugged energy landscapes}

The energy landscape of SARS-CoV-2 and PM dust is rugged due to the possibility of continuous contacts and interactions, among which we consider the non-covalent interactions that combine cooperatively to create complexes. We call them "complex interactions." When non-complex interactions are made, the energy contributions are random.

\section{Postulate 2. The "principle of minimal frustration"}

The rugged landscape is not globally flat but has a preferred direction of flow. There is an overall regular slope of the energy landscape, which is a symptom of cooperativity and synergy. The interactions and conformational energies between SARS-CoV-2 and PM dust are highly stabilizing, until reaching the minimum of entropy. 
Consider therefore the rugged funnel landscape diagram in the following Fig. 10.

We introduce the order parameter " $Q$ " as the percentage of complex-like interactions between SARS-CoV-2 and PM dust, according to the different size and density of PM (as an example, in the scenario of the previous section, we considered a med-hi density for three dust sizes, from 0.025 to $0.100 \mu \mathrm{m}$ ) (See Figs. 8, 9).

The functional dependence of the thermal average energy will be $\bar{E}(Q)$, the ruggedness will be $\sqrt{\Delta E^{2}(Q)}$; the density of states will be $\Omega(E, Q)$; the entropy will be $S(E, Q)$ and the local glass transition temperature will be $T_{g}(Q)$.

In the "ball" stages, as the interaction between the viral particles and dust are random $(Q \approx 0)$, there will be many states and the ensemble average is most appropriate. The hopping rate $\mathrm{R}$ between micro-states at each stage is

$R \approx e^{-\Delta E^{2} / k_{B} T^{2}}$

where $k_{B}$ is the Boltzmann constant and $\mathrm{T}$ is the absolute temperature.

The probability distribution of energies in the interval $\delta E$ at any position in the funnel is a Gaussian centered about the mean energy

$P(E) \delta E=\frac{1}{\sqrt{2 \pi \Delta E^{2}(Q)}} \exp \left\{-\frac{(E-\bar{E}(Q))^{2}}{2 \Delta E^{2}(Q)}\right\} \delta E$

Now, we will define the configuration space.

Consider a spike protein of SARS-CoV-2. If we consider $\gamma$ dust configurations per spike in the ball state $(Q$ $\approx 0$ ), then the total number of configurations for a viral particle with $N$ spikes will be $\Omega_{0}(Q)=\gamma^{N}$.

When the system approaches the state of the complexes, the number of configurations will decrease, until the only configurations will be those of the complexes $(Q \approx 1)$.

If $\Omega_{0}(Q)$ is the number of structures that have a fraction $Q$ of the contacts similar to those in the complexes, then an approximation will be

$\Omega_{0}(Q)=\gamma^{* N(1-Q)}$

where $\gamma^{*}$ is an experimental value for compact configurations. In the case of protein folding, we have $\gamma^{*} \simeq 1.5$ (Frauenfelder et al. 1991; Frauenfelder 1997; Wolynes and Luthey-Schulten 1997).

The entropy will decrease as the complex is approached.

$S_{0}(Q)=k_{B} \log \Omega_{0} \simeq k_{B} N(1-Q) \log \gamma *$
So that in the minimum of the rugged funnel (See Fig. 10 above) we would have compact, closed packed configurations, which precisely are our complexes

$[\mathrm{SARS}-\mathrm{CoV}-2] \oplus[\mathrm{PM}]$.

The density of conformational states with energy $E$ and the order parameter $Q$ will be

$\Omega(E, Q)=\Omega_{0}(Q) P(E)$

Such that the total entropy will be

$S(E, Q)=S_{0}(Q)-k_{B} \frac{(E-\bar{E}(Q))^{2}}{2 \Delta E^{2}(Q)}-k_{B} \log \left(\frac{\sqrt{2 \pi \Delta E^{2}(Q)}}{\delta E}\right)$

where $\delta E$ is large relative to the spacings between energy levels, but small relative to $\sqrt{\Delta E^{2}(Q)}$. At thermodynamic equilibrium (inside the vesicle), the most probable energy will be

$E_{\text {best }}(Q)=\bar{E}(Q)-\frac{\Delta E^{2}(Q)}{k_{B} T}$

The entropy associated with the most probable energy will be

$S\left(E_{\text {best }}, Q\right)=S_{0}(Q)-\frac{\Delta E^{2}(Q)}{2 k_{B} T^{2}}$

The free energy will be

$F(Q, T)=E_{\text {best }}(Q)-T S\left(E_{\text {best }}, Q\right)=\bar{E}(Q)-\frac{\Delta E^{2}(Q)}{2 k_{B} T}-T S_{0}(Q)$

Definitely, free energy has relative minima either near the complex states $(Q \approx 1)$, or near the Ball states $(Q \approx$ $0)$. If we neglect the entropy of the complex states, its free energy will be equal to its internal energy. We thus have states of minimal entropy where the complexes $[\mathrm{SARS}-\mathrm{CoV}-2] \oplus[\mathrm{PM}]$ are stabilized in compact, closed packed structures.

Finally, the local glass transition temperature will be

$T_{g}(Q)=\sqrt{\frac{\Delta E^{2}(Q)}{2 k_{B} S_{0}(Q)}}$

Recall that a transition to a "glassy state" occurs at the temperature where so few states are available such that the system remains frozen in one of few distinct states (Wolynes and Luthey-Schulten 1997; Mezard et al. 2004; Fischer and Hertz 1991; Parisi 1988); ; ; (See Fig. 10 above).

In conclusion, we have complex [SARS-CoV-2] $\oplus[\mathrm{PM}]$, stabilized by strongly cooperative and synergistic conformation interactions and energies. 


\section{Evolution of SARS-CoV-2: mutations and quasi-species}

The evolution of the pandemic virus depends on mutations that give the parasite a selective advantage. A large viral population of SARS-CoV-2 with different genomic sequences is generally called a "quasi-species" or "quasispecies" (Dimmock et al. 2016).

In our landscape model, we can draw a lower risk margin to measure the ability of a quasispecies of SARS-CoV-2 to create a devastating impact on the host.

We can say that a quasispecies of SARS-CoV-2 have sufficient selective advantage to create a devastating impact on the host if the following conditions on entropy, energy and conformations are met, respectively, as follows:

1. $T(Q) \leq T_{g}(Q)$ (temperature of viral quasispecies)

2. the most probably energy of quasispecies is $E_{\text {best }}(Q)=\bar{E}(Q)-\frac{\Delta E^{2}(Q)}{k_{B} T}$

3. the energy variability of quasispecies is given by $\sqrt{\Delta E^{2}(Q)}$ (ruggedness)

All quasispecies that do not meet these conditions do not pose a danger to the host. In particular, the temperature condition (1) means that a dangerous quasispecies must be composed of complexes [SARS-CoV-2] $\oplus[\mathrm{PM}]$. It is clear that the most dangerous quasi-species are found in the neighborhood of $Q \approx 1$ because they are the most stable and resistant. They therefore have the maximum mean destructive action on human health $\langle\aleph(Q \approx 1)>$. Conversely, we must not fear the quasi-species around $Q \approx 0$.

In any case, (3) defines the variability of each quasi-species such as

Ruggedness $=\sqrt{\Delta E^{2}(Q)}$

where

$\sqrt{\Delta E^{2}(Q)} \gg \delta E$

where $\delta E$ is large with respect to the distances between the energy levels, but small with respect to the ruggedness. Finally, our concept of selective advantage will be $\mathrm{W}=\mathrm{W}(\mathrm{S}, \Delta \mathrm{E}, \mathrm{Q}) \approx \mathrm{T}_{\mathrm{g}}(\mathrm{Q})^{2}$.

\section{Landscape prophylaxis}

For effective prophylaxis, we can avoid studying stochastic states $(Q \approx 0)$, focusing only on the viral quasi-species with

1. $T(Q) \leq T_{g}(Q)$

2. $Q \approx 1$

\section{Conclusions and discussion}

In this work, some methodological notes have been addressed concerning the research on the COVID-19 pandemic caused by the new coronavirus SARS-CoV-2.

From a careful examination of the scientific literature in subiecta materia, we have noticed that the current research and characterization of SARS-CoV-2 pandemic virus lack a correct thermodynamic description. In some cases, as in the works referred to here, thermodynamics is completely lacking. In other cases, an attempt has been made to calculate and measure some thermodynamic quantities, such as free energy and temperature, but in the laboratory, i.e. under conditions other than the experimental ones, or (this is the worst error) by algorithmic simulations based on manually adjusted boundary conditions or copied from "similar" conditions, but different from the experimental ones and taken in different spaces and times. In other cases, the measurement conditions were very far from equilibrium, or not reproducible, or vitiated by inadequate statistics. A review ofthese cases will be the subject of a future paper. But the most worrying thing from a methodological point of view is the study of the viral particle in vacuum, which causes a chain of logical absurdities and, therefore, systematic errors that can cast doubt on the results of an entire research.

The viral particle is described and represented in se ipsum, i.e., independently of the environment, as if the viral particle could exist without its environment, in a vacuum (nihil sine causa datum est). Not only in theoretical descriptions and experimental results, but also in biological and biophysical-computational simulations, unfortunately, the origin of this abomination is well known and must be sought in x-ray crystallography of proteins. From here, the crystallographic technique and the software, commercial or tailor-made, of molecular and macro-molecular simulations are unfortunately taken and exported tout-court in the physical world of living matter. From here it is easy for many to build toy models of the dynamics of a viral particle in an empty box. In some cases, the box is also missing, that is, the space-time references, so that the dynamics of the pandemic virus is also found free from a particular region of space-time. But we know, and the present research bears witness to it, that the distribution of the pandemic also depends on geography and on the particular climatic conditions. So, the methodological problems are therefore many. In the present work, we have focused on the thermodynamic environment of the pandemic virus. This seems like a good start. We therefore studied the thermodynamics of SARS-CoV-2 in its "hunting" environment, from air transport to endosome and endosome-independent cell entry pathways. In the study of the thermodynamics of the air environment of the pandemic virus SARS-CoV-2 in air, the presence of pollen, bacteria, 
other viruses, spores, dust, but more particularly, that of nanoparticles of health interest at the same scale threshold as the spike proteins of the pandemic virus, such as particulate matter, cannot be neglected. This work therefore starts from a comparative study of the air environments in China and Italy, the first countries affected by the infection. Currently, a correlation between the spread of infection and pollution is still very controversial. But our paper is not concerned with this. We propose some methodological notes which lead us to the formulation of a general mathematical apparatus (an energy landscape theory), suitable to explain at the molecular level the energetic configurations of the quasi-species of the pandemic virus SARS-CoV-2 in its environment. We focus on complexes between the viral particle and particulate matter in its environment at the scale threshold of the spikes of the viral particle. Then, we wondered if such complexes can lead to the generation of more aggressive viral variants and how to predict their populations and energy configurations, in order to plan an adequate prophylaxis. To do this we trace on the energy landscape some quantities of interest as a function of entropy, glass temperature, energy and the number of configurations, as a function of a control parameter $\mathrm{Q}$ that measures the percentage quantity of non-covalent interactions between spikes and nanoparticles which generate stable complexes. In this way we have a quantitative and qualitative measure of the most dangerous quasi-species. A useful quantity in this sense is that of the selective advantage $\mathrm{W}$, which is proportional to the square of the glass temperature, and the average destructive action $\aleph(Q)$ on human lung and upper airway epithelial cells. We can therefore trace a useful methodological protocol, as follows.

After a correct sampling of the organic materials and the environmental background, in the same space-time intervals and in the same physical conditions, the thermodynamics of the system can be correctly defined according to the observations outlined here. Therefore, viral quasi-species can be analyzed as a function of energies and configurations, from which it is possible to trace an experimental landscape for each micro-area of study, which will guide us in the analysis and simulations, as explained in this work.

The first thing to do is to create a diagram of the viral quasi-species identified so far as a function of the average (free) energies measured in the same environmental conditions as the background. Each geographical micro-region must have its own diagram. For example, we will have the Lombardy diagram for a certain time interval, the Wuhan diagram and so on. For each quasi-species, we will have to identify the danger on the basis of the selective advantage $\mathrm{W}$ and the average destructive action $\aleph(\mathrm{Q})$ on human lung and upper airway epithelial cells, calculated point-to-point by the tables generated and updated from time to time by the health institutes and scientific committees of each country. The intersection of the diagram with the most dangerous species $\mathrm{W}$ and the average destructive action $\aleph(\mathrm{Q})$ on human lung and upper airway epithelial cells, will provide us with some points in the neighborhood of the control parameter $Q \approx 1$. These will be our experimental minima of the free energy, which will help us to build our experimental landscape, which will serve as a condition for outline to proceed with the simulations and models of the evolution of the disease. From which it is easy to calculate the various coefficients such as contagion indices and so on.

We reserve further information and updates.

Acknowledgements The author acknowledges the: Ministry of Environment and Ecology of the People's Republic of China; The European Commission; The European Environment Agency; The U.S. Environmental Protection Agency; World Health Organization; Italian Government; Istituto Superiore di Sanità (Italian National Institute of Health); Prof. Giorgio Parisi, President of the Accademia Nazionale dei Lincei; Regione Lombardia, Italy; The People's Government of Wuhan, China; The World Wildlife Fund - WWF; National Scientific Council of Italy - CNR; Coronavirus Disease Research Community - COVD-19 at CERN, Genève, Switzerland.

\section{References}

Accademia Nazionale dei Lincei (2021) - COVID-19 Commission directed by G Parisi https://www.lincei.it/it/covid-19-documentidellaccademia-dei-lincei

Anenberg SC, Achakulwisut P, Brauer M, Moran D, Apte JS, Henze DK (2019) Particulate matter-attributable mortality and relationships with carbon dioxide in 250 urban areas worldwide. Sci Rep 9(1):11552-11552. https://doi.org/10.1038/s41598-019-48057-9

Cascella M, Rajnik M, Cuomo A et al (2020) Evaluation and treatment coronavirus (COVID-19)—updated 2020 Apr 6, statpearls publishing edn. Treasure Island (FL), USA. https://www.ncbi.nlm. nih.gov/books/NBK554776/

CERN, Geneve, CH (2020a) CERN against COVID-19. https://again stcovid19.cern/

CERN, Geneve, CH (2020b) folding@ home. https://againstcovid19. cern/actions/cern-contributes-computers-combattingcovid-19

CERN, Geneve, CH (2020c) ZENODO-COVID-19 related communities. https://zenodo.org/

CHINA National Environmental Monitoring Centre-CNEMC (2020) PM2.5 concentrations at 1280 stationary sites. http://www.cnemc. $\mathrm{cn} / \mathrm{en} /$

Corriere della Sera (2020-2021) COVID-19 pandemics in Italy The contagion map updated is available at the following. https://www. corriere.it/salute/mappa-coronavirus-italia-dati-contagio-covid19/ index.shtml

Dimmock NJ et al (2016) Introduction to modern virology. In: Introduction to modern virology, 7th edn. Wiley, Oxford

European Environment Agency-EEA (2019) Health impacts of air pollution. https://www.eea.europa.eu/publications/air-quali ty-in-europe-2019

European Environment Agency-EEA (2019-2020) Italy-Air pollution country fact sheet 2019. https://www.eea.europa.eu/themes/air/ country-fact-sheets/2020-country-fact-sheets/italy

Fischer KH, Hertz JA (1991) Spin glasses. Cambridge studies in magnetism. Cambridge University Press, Cambridge

Frauenfelder H (2005) Energy landscape and dynamics of biomolecules extended abstract. J Biol Phys 31(3-4):413-416. https://doi.org/ 10.1007/s10867-005-0696-4 
Frauenfelder H, Sligar S, Wolynes P (1991) The energy landscapes and motions of proteins. Science 254(5038):1598-1603. https://doi. org/10.1126/science. 1749933

Frauenfelder H (1997) The complexity of proteins. In: Physics of biological systems. Springer, New York

Friedlander SK, NSF, Southern California Particle Center, and UCLA Department of Chemical Engineering et al (2003) Emerging issues in nanoparticle aerosol science and technology (NAST). http://www.eng.uc.edu/ beaucag/Classes/MorphologyofCom plexMaterials/NSFAerosolPar\%20Report.pdf

$\mathrm{He} \mathrm{MZ}$ et al (2017) Fine particulate matter concentrations in urban Chinese Cities, 2005-2016: a systematic review. Int J Environ Res Public Health. https://doi.org/10.3390/ijerph14020191

Italian Society of Enviromental Medicine (2020) Position paper and "Relazione circa l'effetto dell'inquinamento da particolato atmosferico e la diffusione di virus nella popolazione". https://www. simaonlus.it/?page_id $=694$

Kuerban M et al (2020) Spatio-temporal patterns of air pollution in China from 2015 to 2018 and implications for health risks. Environ Pollut. https://doi.org/10.1016/j.envpol.2019.113659

Liang D et al (2019) National air pollution distribution in China and related geographic, gaseous pollutant, and socio-economic factors. Environ Pollut 250:998-1009. https://doi.org/10.1016/j.envpol. 2019.03.075

Liu D, Lin T, Syed JH (2017) Concentration, source identification, and exposure risk assessment of PM2.5-bound parent PAHs and nitro-PAHs in atmosphere from typical Chinese cities. Sci Rep 7:10398-10398

Liu $\mathrm{Y}$ et al (2020) Aerodynamic characteristics and RNA concentration of SARS-CoV-2 Aerosol in Wuhan Hospitals during COVID-19 Outbreak. bioRxiv. https://doi.org/10.1101/2020.03.08.982637

Lombardia R, Regione Lombardia (2020) Lombardy territory and population. https://www.regione.lombardia.it/wps/portal/istit uzionale/\%20HP/DettaglioRedazionale/scopri-la-lombardia/Terri torio-e-popolazione/\%20Territorio+e+popolazione/red-territorioe-popolazione-REC

MacNee W et al (2003) Mechanism of lung injury caused by PM10 and ultrafine particles with special reference to COPD. Eur Respir J 40:47s-51s. https://doi.org/10.1183/09031936.03.00403203

Mezard M, Parisi G, Virasoro M (2004) Spin glass theory and beyond. World Scientific, Singapore

Ministry of Ecology of the People's Republic of China (2017) Report on the state of the ecology and environment in China 2017. http:// english.mee.gov.cn/Resources/Reports/soe/SOEE2017/201808/ P020180801597738742758.pdf

Oberfield B, et al. (2020) COVID-19 snapshot. Cell. https://www.cell. com/pb-assets/products/coronavirus/CELL_11362_S5.pdf

Parisi G (1988) Statistical field theory. Frontiers in physics. AddisonWesley Publishing Company, New York

Pasini A, CNR-Consiglio Nazionale delle Ricerche (2020) Climate change and COVID-19 in an equation. http://www.cnrweb.tv/ cambiamenti-climatici-e-covid-19-in-unequazione/

Peacock TP, Goldhill DH, Zhou J, Baillon L, Frise R, Swann OC, Kugathasan R, Penn R, Brown JC, Sanchez-David RY, Braga L, Williamson MK, Hassard JA, Staller E, Hanley B, Osborn M, Giacca M, Davidson AD, Matthews DA, Barclay WS (2021) The furin cleavage site in the SARS-CoV-2 spike protein is required for transmission in ferrets. Nat Microbiol 6(7):899-909. https:// doi.org/10.1038/s41564-021-00908-w

Pratesi I, Galaverni M, WWF Italia et al (2020) Pandemie, l'effetto boomerang della distruzione degli ecosistemi. https://www.wwf. it/pandemie_e_distruzione_degli_ecosistemi/

Ren M et al (2017) The short-term effects of air pollutants on respiratory disease mortality in Wuhan, China: comparison of timeseries and case-crossover analyses. Sci Rep. https://doi.org/10. 1038/srep40482
Rohde RA, Muller RA (2015) Air pollution in China: mapping of concentrations and sources. PLoS ONE 10(8):e0135749-e0135749. https://doi.org/10.1371/journal.pone.0135749

Rongshan Wu et al (2018) Are current Chinese national ambient air quality standards on 24-hour averages for particulate matter sufficient to protect public health? J Environ Sci (china) 71:67-75. https://doi.org/10.1016/j.jes.2018.01.017

Scientific Committee on Health and Environmental Risks-SCHER (2005) New evidence of air pollution effects on human health and the environment. https://ec.europa.eu/health/archive/ph_risk/ committees/04_scher/docs/scher_o_009.pdf

Setti L et al (2020) (2020) Potential role of particulate matter in the spreading of COVID-19 in Northern Italy: first observational study based on initial epidemic diffusion. BMJ Open 10(9): $\mathrm{e} 039338$

Scientific Committee on Emerging and Newly Identified Health Risks (SCENIHR) at the European Commission (2006) The appropriateness of existing methodologies to assess the potential risks associated with engineered and adventitious products of nanotechnologies. https://ec.europa.eu/health/ph_risk/documents/synth_ report.pdf

Trewyn B et al (2008) Biocompatible mesoporous silica nanoparticles with different morphologies for animal cell membrane penetration. Chem Eng J 137(1):23-29. https://doi.org/10.1016/j.cej. 2007.09.045

The Government of Wuhan (2020) Wuhan population and territory. http://english.wh.gov.cn/whgk_3581/dqrk/201809/t20180913_ 227369.html

United States Environmental Protection Agency-EPA (2020) Particulate matter (PM) pollution. https://www.epa.gov/pm-pollution/ health-and-environmental-effects-particulate-matter-pm

Walls AC et al (2020) Structure, function, and antigenicity of the SARS- CoV-2 spike glycoprotein. Cell 181(2):281-292.e6. https:// doi.org/10.1016/j.cell.2020.02.058

Wang $\mathrm{H}$ et al (2008) SARS coronavirus entry into host cells through a novel clathrin- and caveolae-independent endocytic pathway. Cell Res 18(2):290-301. https://doi.org/10.1038/cr.2008.15

Wang W, Zhao S, Jiao L (2019) Estimation of PM2.5 concentrations in China using a spatial back propagation neural network. Sci Rep 9:13788-13788

Wolynes PG, Luthey-Schulten Z (1997) The energy landscape theory of protein folding. In: Physics of biological systems. Springer, Berlin

Wu X, Nethery RC, Sabath MB, Braun D, Dominici F (2020) Air pollution and COVID-19 mortality in the United States: strengths and limitations of an ecological regression analysis. Sci Adv 6(45):4049

Wu MX et al (2020) Exposure to air pollution and COVID-19 mortality in the United States: a nationwide cross-sectional study. MedRxiv preprint. https://doi.org/10.1101/2020.04.05.20054502v1

Xing YF et al (2016) The impact of PM2.5 on the human respiratory system. J Thorac Dis 8(1):E69-E74. https://doi.org/10.3978/j.issn. 2072-1439.2016.01.19

$\mathrm{Xu}$ D et al (2020) Acute effects of ambient PM25 on lung function among schoolchildren. Sci Rep. https://doi.org/10.1038/ s41598-020-61003-4

Yan R et al (2020) Structural basis for the recognition of the SARSCoV- 2 by full-length human ACE2. Science. https://doi.org/10. 1126/science.abb2762

Zhang Y, Cao F (2015) Fine particulate matter (PM2.5) in China at a city level. Sci Rep 5:14884-14884

Zhang L et al (2020) Crystal structure of SARS-CoV-2 main protease pro-vides a basis for design of improved $\alpha$-ketoamide inhibitors. Science. https://doi.org/10.1126/science.abb3405

Zhao B et al (2018) Change in household fuels dominates the decrease in PM2.5 exposure and premature mortality in China 
in 2005-2015. PNAS 115(49):12401-12406. https://doi.org/10. 1073/pnas.1812955115

Zhu Y et al (2018) Sources of particulate matter in China: insights from source apportionment studies published in 1987-2017. Environ Int 115:343-357. https://doi.org/10.1016/j.envint.2018.03.037
Publisher's Note Springer Nature remains neutral with regard to jurisdictional claims in published maps and institutional affiliations. 